\title{
Planning Guideline for Three Tires Government of Nepal
}

\author{
Dipak Bahadur Adhikari (i) \\ Patan Multiple Campus, Tribhuvan University, Kirtipur, Nepal \\ Email: dbadhikari10@gmail.com
}

How to cite this paper: Adhikari, D. B. (2021). Planning Guideline for Three Tires Government of Nepal. Theoretical Economics Letters, 11, 558-571.

https://doi.org/10.4236/tel.2021.113037

Received: March 3, 2021

Accepted: June 21, 2021

Published: June 24, 2021

Copyright $\odot 2021$ by author(s) and Scientific Research Publishing Inc. This work is licensed under the Creative Commons Attribution International License (CC BY 4.0).

http://creativecommons.org/licenses/by/4.0/

\begin{abstract}
The country fully entered into the Federal Structure of political governance through implementation of the Federal Constitution. The planning process also would have to redefine and readjust according to change in the country to keep the development spirit by setting national goals and objectives down to the lower tiers of the government. Therefore, it is pertinent to define the clear role and responsibilities of all stakeholders involved in the planning process of the country. This study has tried to address those issues by explaining frictional role, planning process and relationship among all planning units at each tier of government. National Planning Commission (NPC) has to interpret the goal into policy and program and send it to Provincial Government for further analysis and process as per the requirement of such Government. The Local Levels prepare their own plans and policies in line with the directives received from the NPC and send them both to the provincial planning entities and the NPC. A two-way algorithm of planning process both top-down and bottom-up will be in practice and they will be adjusted when necessary basis.
\end{abstract}

\section{Keywords}

Planning, National Planning Commission, Local Level, Government

\section{Introduction}

Planning is an appropriate development path to improve the economic condition of a country. Planning is in essence, an organized, conscious and continual attempt to select the best available alternatives to achieve specific goals (Waterston et al., 1965). The need for planning arises from the inability of the price mechanism to ensure growth, efficiency and equity (Shakya, 2007). Nepal started 
development planning in 1956, after the demolition of the Rana Regime which has been considered as the first turning point in economic development of Nepal. However, after more than five decades of planned development, Nepal's development process has been slower than expected, raising concerns about the effectiveness of the country's development planning system and institutions (Asian Development Bank, 2009).

The main roles of the three tiers of government in public service delivery have emerged as one of the most important topics of open and vigorous debate (Khemani, 2001). Three-dimensional planning embraces the task of integrating the economic, social and environmental dimensions of territorial strategies with the ultimate aim of ensuring that development outcomes are sustainable (Acheampong \& Ibrahim, 2016; Counsell et al., 2006; Vigar, 2009; Roseland, 2000).

In mixed-economy with federal governments, constitutional provisions generally require the federal government to share responsibility for planning in varying measure with its political subdivisions. Because, most of the countries local governments are delegated with complex task related to people's welfare such as health care, education, housing environmental protection extra. So, when a country with a federal government begins to plan, this usually leads to the establishment of planning machinery at the provincial level and local level.

With the change in time, the opportunities and challenges also change in Nepal. Because of changing nature of opportunities and challenges, the development plans have been found taking new turns in the course of time (Srivastava, 2008). However, the plan could not achieve its objectives as anticipated due to the lack of proper knowledge about planning process, broad ideas about economic development, institutional arrangement, and the vested interest between the power centers.

The Constitution of Nepal 2015 changed the governing system of Nepal from unitary to a three-tier federal structure constitutionally deriving the role and responsibilities of each tier. Under the present process of state transformation, the detailed role and responsibilities of all tiers of governments are well defined by constitution. The need of the provincial and local level planning entities for the guidance for preparing development plans and supervision during their implementation is essential. The linkages between the National Planning Commission (NPC) and all tiers of governments during the preparation of development plan and their implementation are also equally essential to be outlined.

The research structure is organized into five sections. The second section includes objectives of the research; the third section discusses the methodology; section four is the data presentation and analysis and the last section concludes the entire study.

\section{Objectives}

The objectives of this study are to identify and analyze the structure of Planning Institution at all level and to identify the vertical and horizontal linkages among 
NPC and planning entities at provincial and local level.

\section{Methodology}

The methodology used to undertake this study was descriptive method, reviewing literature and documents with limited field work. Several consultative meetings with planning experts and bureaucrats were conducted to capture the planning and execution process including potential difficulties in implementation of the project and program. This study explores issues and context emerged from recent changes and amendment of the policy framework of NPC in line with the macroeconomic modeling to link down at the lowest level of governance.

\subsection{Methodological Approach}

This study based on both primary and secondary data for primary data the researcher used consultative meeting with the key stakeholders from central level to all levels of government as far as possible. One unit at each tier had been selected for interview and consultative meeting. The total number of interviewees was 34 selected by using purposive judgmental sampling procedure. International practices in implementation of the national policies at sub-national level of government of the federal state were also reviewed.

Under the federal set-up of Nepal there are 761 elected governing bodies. All those elected bodies will have their distinctive and shared powers, functions, roles and responsibilities mandated from the Constitution 2015. They will also have respective autonomous bodies for the governance.

\subsection{Sample Selection}

Purposive judgmental sampling procedure was applied to make the sample representative for Hill, Terai, and Mountain also covering from east to west part of the country. The sample also had covered the political units: at least one political governing unit from Metropolitan city, Municipality, Rural Municipality.

\subsection{Source of Information}

The consultative meetings with the Mayors, Deputy Mayors, Executive Officers, Accountants, planning officers of local levels were conducted. The information was collected from the representatives of civil societies as well. A set of open-ended questionnaires was used to collect the opinion of the respondents. Open-ended questions allow the respondent to express an opinion without being influenced by the researcher (Foddy \& Foddy, 1994). This has several consequences for the quality of survey data for researcher (Reja et al., 2003).

\section{Data Presentation and Analysis}

\subsection{Planning Process in Nepal}

National Planning Commission sets the national development goals based on the 
broader policy guidance of Constitution, commitment made by the Government to the public and their declaration; feedback received for previous periodic plans; international commitments (e.g. SDGs); analysis of public needs; and evaluation of the development indicators and resource availability. The periodic Plans are formulated to achieve the national goals, with the identification of roles and responsibilities of sectoral ministries and authorities. The overall planning process also considers sustainability of development financing in Nepal (Figure 1).

Multiple institutions are involving in the planning under the institutional framework according to the role and responsibilities defined. The NPC leads the entire planning preparation but institutions such as Cabinet, Resource Committee, Steering Committee, Ministry of Finance, Ministries of Taskforce, Sectoral Committee and Line Ministries and their division and other entities are also involved.

Normally, NPC formulates five-year development Plans. However, since last few years three-year Plans are being formulated. The idea behind formulating three-year Plans was to lay the foundation for long term planning in Nepal in the expectation that the political transition would be over and stable government takes charge of development process. Because of lingered political transition, NPC ended up formulating four consecutive three-year plans. The above section details out the planning process in the country.

The following institutions and entities are broadly involved in the planning process of Nepal:

1) National Development Council (NDC) - to provide broad direction for the planning.

2) National Planning Commission—to formulate the Plans on the basis of direction provided by NDC.

3) Line Ministries-to set the sectoral targets, sectoral priorities, strategies, objectives and working policies.

4) Ministry of Finance-to project the resources and facilitate the overall planning process.

5) Ministers' Council (Cabinet) - to approve and execute the plan.

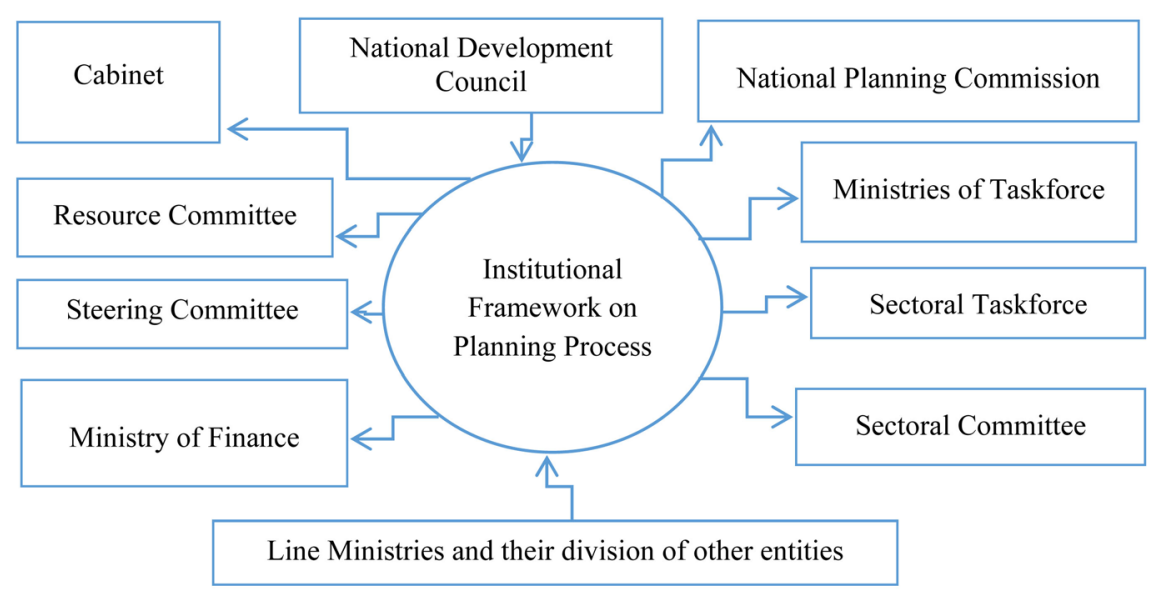

Figure 1. Flow of national policy framework by the responsible agencies. 


\title{
4.2. Federal Planning Mechanism
}

The three layers of planning mechanism will be in existence with their well-defined role and responsibilities, scope of works and procedures. The National Planning Commissions' roles will be policy formulation, suggestion and regulation for overseeing the provincial and Local Level particularly in monitoring, supervision and evaluation in plan implementation.

A provincial government planning commission will have shared responsibilities linking with federal government and the Local Level. The Provincial Planning Commission (PPC) will be more focused on preparation of province plan policies and will also endorse the national development goals of the NPC.

The Local Level will have distinctive role on service delivery to the local people. The Local Planning Unit will be responsible to collect baseline information for service delivery, infrastructure development in line with the guidelines of the NPC and the PPC. The below chart explains the planning mechanism of the federal Nepal.

\subsection{National Planning Commission}

The National Planning Commission (NPC) is formed as a specialized entity, in order to formulate development policy and plan focusing on long-term vision and balanced and sustainable development for the rapid economic progress in Nepal. The National Planning Commission (NPC) is the apex advisory body of the Government of Nepal for formulating a national vision, periodic plans and policies for development.

The NPC is headed by the Prime Minister. At present, the NPC has one full-time Vice-Chairman, six members, and one Member-Secretary who also heads a fully staffed secretariat. The Chief-Secretary and the Finance Secretary are ex-officio members of the Commission. The national statistical organization of Nepal, the Central Bureau of Statistics (CBS), functions as a specialized entity of the NPC Secretariat, headed by a Director-General.

\author{
Structure of National Planning Commission \\ Chairman: Prime Minister \\ Vice-Chairman: Government Appointee \\ Member: Six Government Appointees including at least one female \\ Ex-Officio Member: Chief Secretary \\ Ex-Officio Member: Secretary, MoF \\ Member Secretary: Secretary, NPC \\ Source: (National Planning Commission Formation Order, 2074)
}

\subsection{Provincial Planning Commission}

As the NPC sets national goals; prepares national policies and guidelines; prepares national plan; coordinates among all tiers of government and develops guidelines for monitoring and evaluation, the responsibility of preparing overall de- 
velopment plan within the jurisdiction of the Provincial Government lies on the Provincial Planning Commission (PPC). The NPC sets the national targets for different sectors and the PPC should prepare province level plan with strategies to achieve those targets. Similarly, the national development goals and the related policies need to be translated in the plan/programs/projects formulated by the newly established Provincial and Local Level. Furthermore, the coordination between policy formation and implication at functional level is also equally important under the present status of the institutional capacity of the Local Levels.

Thus, a province level planning commission has been appeared imperative and have also been consistently suggested for its' formation by the respondents of the seven different Local Levels. Therefore, the Provincial Government should form/establish a province level planning commission to formulate province level plan, to coordinate for the implementation of the plan and program as well as for monitoring \& evaluation of such plan and programs within the jurisdictions and territories of the PG. The PPC positions in the middle of other two tiers of planning entities involved in plan and policy formation and implementation respectively. The PPC should be more careful on distinctive and shared functions, roles and responsibilities of each tier of governments while preparing province level policy and plan.

The structure of the Provincial Planning Commission has been suggested as below:

\section{Structure of the Provincial Planning Commission \\ Chairman: Chief Minister \\ Vice Chairman: Province Government Appointee \\ Member: Chief Secretary, Provincial Government \\ Member: Deputy Chief, PG}

Members: Five PG Appointees including at least two female members

Member: Secretary, Ministry of Economic Affairs and Planning, PG

Member Secretary: Secretary, Provincial Planning Commission Secretariat

\subsection{Local Planning Unit}

The Local Government Operation Act 2017, Part 3, Article 11 has explained the functions roles and responsibilities of the Local Level in line with the distinctive functions roles and responsibilities specified in Schedule 8 of the Constitution of Nepal. The LL has to make a mid/short-term, periodic plan and local development strategies in order to implement such function, role and responsibility systematically. The Local Level plays a significant role in functionalization of the whole planning and development process by preparing local level development plan, including unit level cost estimation, based on policy and guidelines provided by the upper tiers of the governments; preparing the functional level project/programs for upper tiers; allocating the resources by developing certain priority sectors; as well as facilitating/coordinating in project implementation, monitoring 
and evaluation.

Therefore, the Local Level should establish a Local Planning Unit to undertake the constitutionally delegated functions, roles and responsibility formulating local level periodic plan and short/mid-term development strategies. The Unit will be further guided by the Revenue Projection and Budget Ceiling Determination Committee and the Budget and Program Formulation Committee which are provisioned respectively on Articles 66 and 67 of the Local Government Operation Act, 2017.

The Proposed Structure of the Local Planning Unit

Chairman: Chief of Local Level

Member: Deputy Chief, Local Level

Member: Planning Expert, LL Appointee

Member: Two Representatives from Ward Committees

Member Secretary: Planning Officer, LL

\subsection{Vertical and Horizontal Linkages}

\subsubsection{Planning Relationship among Three Tiers of Government}

On the one hand, the guidelines are supposed to ensure that decentralized development plans are well linked to the overall National development strategic direction as well as to the sector development goals. On the other hand, the guidelines are also supposed to ensure intra and inter agency synergies and linkages in the local government planning framework (Local Government Development Planning Guidelines, 2014). The Federal Government, Provincial Government and Local Level have constitutionally assigned distinctive and shared functions, roles and responsibilities. The three tiers formulate national, province and local level plan within the jurisdiction of the respective tiers. The planning entities formulate the plan focusing on the independent and shared functions, roles and responsibilities of the respective governments. Furthermore, there should be a sound relationship/coordination between the planning entities; and between the governments in preparation, coordination/facilitation, and monitoring and evaluation of the long-term, short-term, periodic and annual plan. The framework of the relationship/coordination shall be as below.

\subsubsection{Relationship of Federal Government with Lower Tiers of Governments}

Inter-governmental relationships among the planning units at each level both in institutional and planning procedure should be linked.

- The National Development Council will lead to define national development goals and objectives. In the NDC, the Prime minister of Federal government will chair the council and there will be participation from the Provincial government. Preferably the Chief Ministers of all provincial government will join the NDC along with the respective Province Finance Ministers. The secretary of the NPC will be appointed as member Secretary for the NDC. And the 
Chief Secretaries of PG will be Assistant Governor of the NDC. The NDC meeting will be held on when and necessary upon the direction of the Chairman.

- The NPC and the PPC will be responsible to set the budget ceiling and will design the guidelines and directives for implementation of both national provincial development plan at local level.

- The Federal Government can take third party evaluation and effectiveness study of the plan at all three tiers of governments.

- A common standard operational manual will be prepared for formulation, implementation, impact evaluation and capacity enhancement of human resources.

- Comprehensive integrated coordination framework to link all development projects in the web needs to be established and make them accessible to all levels of governments.

\subsubsection{Relationships across Province and Other Tiers of Governments}

Provincial Government will have intermediaries' roles to liaison to Federal Government and oversight role over the lower-tiers of government. The Local Government Operation Act 2017 has provisioned to establish a Provincial Coordination Council to review, monitor and supervise of development activities.

- Provincial Coordination Council will be formed according to the prevailing legal provision. The council will lead by Chief Minister as coordinator and members will be all ministers from provincial sate, chief secretary provincial province, chief and deputy chief, District Coordination Committee, Mayors and deputy mayors from all Metropolitan, sub-metropolitan, Urban and rural Municipalities; and member secretary of the council will be the Secretary of Ministry of Local Governance from Council of Province Cabinet Ministries.

- The Province Planning Commission coordinates the DCC and local bodies in designing and implementation of the development plan within their territories. The PPC will maintain functional relationships with all stakeholders both monitoring supervision and execution of the project and plan.

- The PPC will also keep close coordination and contact with NDC and sends information in central level monitoring and evaluation web portal designed to bring all planning units down to Local Level.

- Vertical and horizontal hierarchy will be established for transformation and sharing of information on project design, coordination, supervision, monitoring and evaluation, progress review and control mechanism among the development institutions at all level concerned.

4.6.4. Local Planning Unit and Its' Relationships with Other Stakeholders A common standard planning tool applicable to all planning units developed by NPC will be used by the local planning units for uniformity of monitoring and evaluation of plan and projects. Sustainable development approach at local level will be appropriate. Empowered local planning unit is the strong foundation of 
sustainable self-operating planning in implementation of project which could be in operation smoothly after completion and hand over to the authorities.

- Local planning unit should be more responsible as their role is distinctive on service delivery accountability in every aspect because they are directly connected with the local people/end users' service. They have more responsibilities than the other planning institutions as they must follow the guidelines received from their superior planning entities and must submit report in their local governing council and must send them to their superior offices as well.

- The local levels take responsibilities of protection, maintenance, coordination of the all types of projects and programs in their territories. They must keep the inventory and assets generate in their territories and should send the record of assets to the Provincial Government and Federal.

- The baseline data collected at local level should be analyzed compiled and need to keep in its archive. Those data should be shared with federal and provincial governments.

LL should involve local service users and stakeholders as far as possible in formulation of the project plan down toward level. And all wards should be brought in to their network and web interface.

The above linkages can be further explained by below chart showing vertical and horizontal relations (Figure 2).

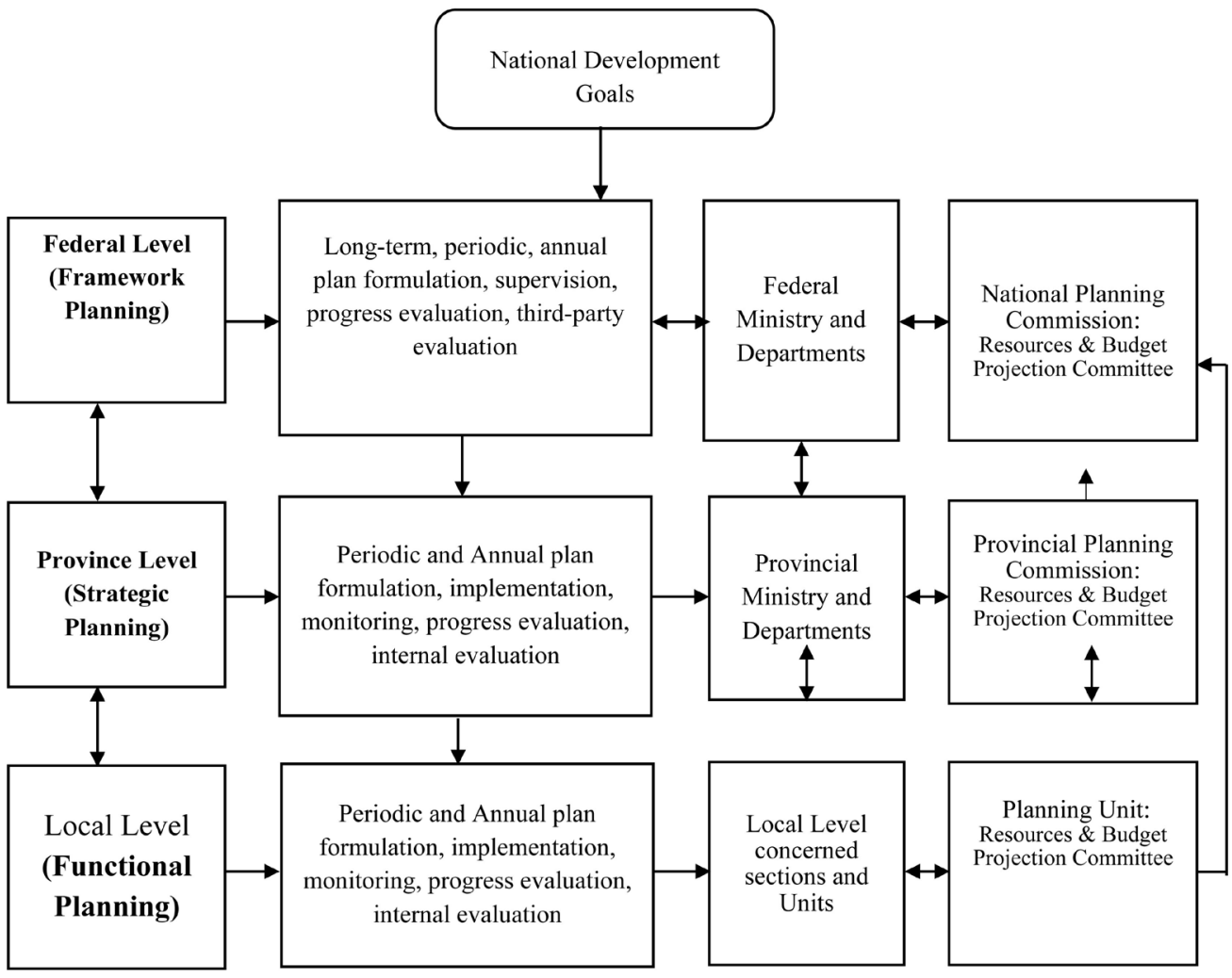

Figure 2. Relationship between three tiers of the government. Source: Taskforce study report formulated by the NPC on 2073/09/25. 


\subsection{Vertical Relationships among Federal Government, Province Government and Local Levels}

There will be two-way vertical relationship between the federal government, the Province government and the Local Level government and their respective planning entities during the different phases of plan which can be further categorized in functional relationship and resource wise relationship.

\subsubsection{Relationship in Policy Translation}

In the preparation, implementation and monitoring and evaluation of long-term, periodic and annual plans a vertical relationship shall be maintained between the planning entities of the FG, PG and LL. The National Planning Commission sets the National Development Goals and formulates related policies to achieve them. The Provincial Planning Commission prepares strategic plan for overall development of the Provincial Government translating the goals set by the NPC. The Local Level prepares the periodic and annual plan translating the national goals and policies at functional level. The below chart will show the relationship (Figure 3).

\subsubsection{Vertical Relationship in Coordination, Monitoring \& Evaluation}

The NPC, as the apex body in planned development of Federal Nepal, develops the monitoring and evaluation guidelines and tools applicable for all tiers of governments. The NPC conducts monitoring and evaluation of macroeconomic policy implementation, national level programs/projects operated by the FG, and other strategically important programs/projects even operated by the PG and the LL. It can coordinate with the PG and the LL for the monitoring and evaluation of the centrally operated particular projects and delegates authority within their respective jurisdiction.

National goals setting, policy formulation, national plan formulation, tier-wise coordination, monitoring and evaluation

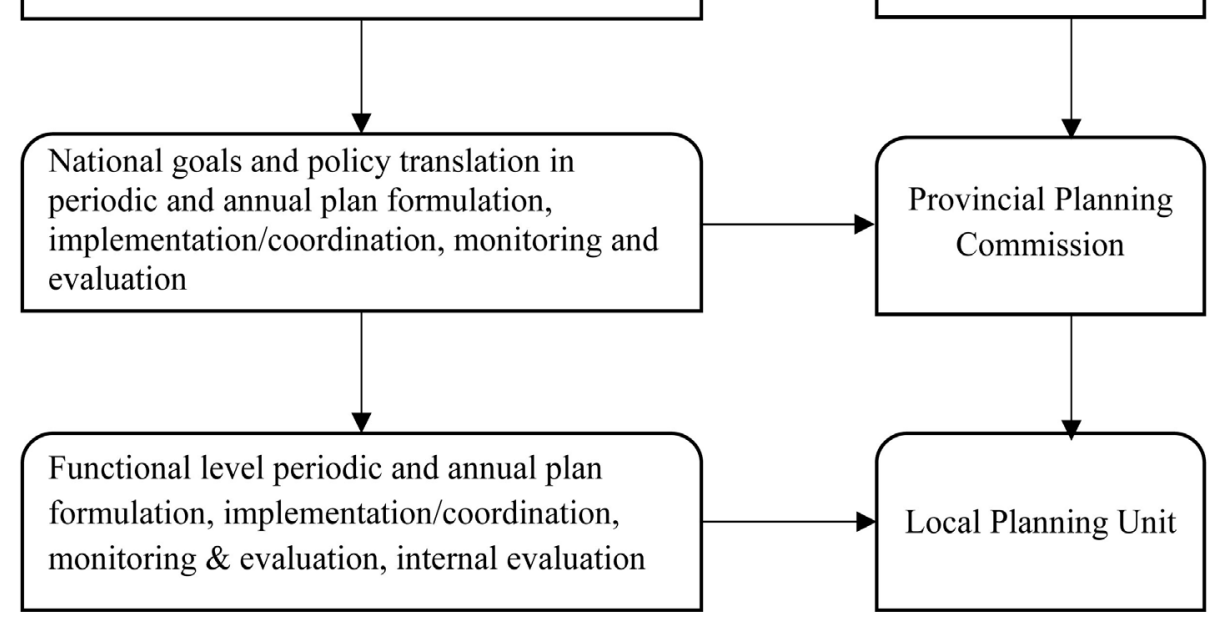

Figure 3. Policy translation. 
The Province Planning Commission conducts the monitoring and evaluation of province level programs/projects based on the monitoring and evaluation guidelines developed by the NPC. The PPC conducts the M \& E of the province level projects/programs; the national level and national pride projects/programs implemented under its' jurisdiction upon the authority delegated by the NPC and the programs/projects even operated by the LLs to ensure the national/province development goals and policy incorporation in the implementation.

\subsection{Horizontal Relationship of Three Tiers of Governments}

The FG, PG and LL will have horizontal linkage with the institutions that involves in plan formulation, coordination/supervision of the respective governments.

\subsubsection{Horizontal Relation in Plan Formulation}

In the process of planning, each tier of the government will have to consult the government ministries and departments, unit offices and other development stakeholders established within the jurisdiction of the respective governments. The relation can be explained as below:

Central Level: The National Planning Commission will coordinate/consult with the NNRFC, the MoF and other federal ministries and departments; national level NGOs and other development stakeholders, International Development Partners (Through Ministry of Finance), and other relevant stakeholders that directly/indirectly involve in the process of planning. The coordination with such entities is significant while formulating plan under shared responsibilities.

Province Level: The Provincial Planning Commission in coordination with Province Ministry of Economic Affairs and Planning, consults with the other province ministries and departments, province level semi-governmental organization, District Coordination Committees within the province, neighboring Provincial Government, province level NGOs, other individual experts and development stakeholders in formulation of plan.

Local Level: The Local Planning Unit, in close coordination with Resource Projection and Budget Limit Determination Committee and Budget and Program Formulation Committee, consults with concerned sections/units of the LL, local level office of the FG and PG, neighboring Local Levels, the NGOs, consumer groups and cooperatives, and other community based firms and intellectuals in order to prepare the local level plan.

\subsubsection{Horizontal Relationship in Coordination and Supervision}

The planning entities of different tiers will coordinate with the institutions established on respective tiers for project/program design; implementation; supervision and control; coordination and monitoring and evaluation.

National Level: The NPC will coordinate with the concerned wing of the Office of the Prime Minister and Council of Minister, the Supervision, Monitoring 
and Evaluation Division/Section of the federal ministries and departments, the FCGO, and other institutions established for the implementation of national level programs/projects.

Province Level: The PPC in consultation with concerned divisions/departments of the Ministry of Economic Affairs and Planning coordinates and supervises the programs and projects operating within the jurisdiction of the Provincial Government. Furthermore, the PPC consults with the province and district level organizations of the Federal Government, District Coordination Committees within the province, and other institutions established for the project/program implementation.

Local Level: The Local Planning Unit consults with the Resource Projection and Budget Ceiling Determination Committee, the Budget and Program Formulation Committee and concerned divisions/sections of the local level for the program/project coordination and supervision. In addition, The LPU consults the neighboring Local Levels for the coordination and supervision of the programs/projects operated under shared responsibilities.

\subsection{Plan Implementation}

A comprehensive plan implementation guideline will be required for information sharing, implementation status analysis, establishment of intergovernmental planning process, Monitoring and Evaluation and supervision among the three tiers of government.

The major issues in planning process such as project prioritization, resources planning, adroit human resources, common role, responsibility and functions, process flow and interrelationship particularly within the vertical institutions and stakeholders are determines the intergovernmental institutional planning procedure in the Federal Context.

\subsection{Monitoring and Evaluation}

Monitoring and evaluation of comprehensive Federal Development plan developed by all tiers of planning units of government is a major challenge. The multitiered web-based institutional capacity and organization is required to address the sequential governance of the federal planning containing the methodologies bringing all of them in manageable information and data sharing procedures. Quantifiable physical and financial indicators should be set for the progress achievements factors analysis with respect to time and resources utilization. The plan preparatory activities rely on both primary and secondary base-line data; therefore, the M \& E process fundamentally will have to be based on the base line data gathered before implementation of the project and potential change along during the implementation process.

Multi-tiers monitoring tools linking all the government portfolio would enable to analyze all tiers of government about implementation progress of the project. 


\section{Conclusion}

The NPC is responsible to make road map for macroeconomic development and planning process in the federal context of Nepal including the Federal Government, Provincial Government and Local Level. An equitable and balanced economic development in all tiers of government offering high level of services and welfare to the people is the key phenomenal responsibility and justice under federalism.

The elected representatives as well as the local level personnel must increase/enhance their capacities to know how the planning and development activities connect vertically with the planning entities to translate the national development policies to operationalize at local level. Therefore, the focus of the NPC in federalism will be to elaborate the role of Provincial Government and Local Level in execution of such policies and programs at all tiers of the governments as well as to address the issues faced during their execution.

The knowledge transfer and management to the local level on service deliveries, security mechanism and development factors are the key elements of development management. These issues need to be categorically defined and cascading them into program with timeline and deliveries magnitudes.

Newly elected representatives and institutions at province and local level are in process of institutionalization. Their roles and responsibilities are not yet clear completely as the laws and bylaws at central level to local level are in process of formulation and they must be approved by the respective House of Representatives. Development management plan also should be carried on side by side as in the process of institutionalization of political system. Role and responsibilities of planning units at all level on integrated development plan formulation and execution should be clearly defined with well-presented organogram bringing all planning units in structured network of chain of command and communication.

Three tiers of organizational structures of the planning units will be in existence in each tier of government, however their role and responsibilities and terms of reference vary according to their weight provisioned according to the constitution of Federal Nepal. Functional role of the respective planning units will be determined and endorsed by the governments at all levels.

Metropolitan, Sub-Metropolitan, Municipalities and rural municipalities have got distinctive responsibility for public service delivery and revenue-raising. They get intergovernmental grants transfer from Federal and Provincial Governments. To utilize internal resources and block fund received from the central level they should have transparent and accountable governance system. Therefore, calendar and activities-based, result-oriented planning process is required in formulation and implementation plan/program at local level. Here, the guide line for three tiers of organizational structure planning is presented based on the anticipation of future happenings. But future is uncertain and dynamic. Therefore, this research will be helpful for the researchers for further research. 


\section{Conflicts of Interest}

The author declares no conflicts of interest regarding the publication of this paper.

\section{References}

Acheampong, R. A., \& Ibrahim, A. (2016). One Nation, Two Planning Systems? Spatial Planning and Multi-Level Policy Integration in Ghana: Mechanisms, Challenges and the Way Forward. Urban Forum, 27, 1-18. https://doi.org/10.1007/s12132-015-9269-1

Asian Development Bank (2009). Nepal: Institutional Strengthening of the National Planning Commission. Mandaluyong: Asian Development Bank. https://www.adb.org/sites/default/files/project-document/64645/42157-nep-tar.pdf.

Counsell, D., Allmendinger, P., Haughton, G., \& Vigar, G. (2006). Integrated Spatial Planning-Is It Living Up to Expectations? Town and Country Planning, 75. https://www.research.manchester.ac.uk/portal/en/publications/integrated-spatial-plan ning--is-it-living-up-to-expectations(d4d54c6c-904a-469b-b921-4806231afe83).html

Foddy, W., \& Foddy, W. H. (1994). Constructing Questions for Interviews and Questionnaires: Theory and Practice in Social Research. Cambridge: Cambridge University Press. https://doi.org/10.1017/CBO9780511518201

Khemani, K. (2001) Fiscal Federalism and Service Delivery in Nigeria: The Role of States and Local Governments. Washington DC: World Bank.

Local Government Development Planning Guidelines (2014). Uganda Vision 2040, the Republic of Uganda Retrieved. http://npa.go.ug/wp-content/uploads/LG-PLANNING-GUIDELINES.pdf

Reja, U., Manfreda, K. L., Hlebec, V., \& Vehovar, V. (2003). Open-Ended vs. Close-Ended Questions in Web Questionnaires. Developments in Applied Statistics, 19, 159-177.

Roseland, M. (2000). Sustainable Community Development: Integrating Environmental, Economic, and Social Objectives. Progress in Planning, 54, 73-132. https://doi.org/10.1016/S0305-9006(00)00003-9

Shakya, R. K. (2007). Formulation of Development Plans-Planning Techniques. Administration and Management Review, 19, 8-16.

Srivastava, N. L. (2008). Major Turns in Planned Development of Nepal. Journal of Nepalese Business Studies, 5, 1-15. https://doi.org/10.3126/jnbs.v5i1.2080

Vigar, G. (2009). Towards an Integrated Spatial Planning? European Planning Studies, 17, 1571-1590. https://doi.org/10.1080/09654310903226499

Waterston, A., Martin, C. J., Schumacher, A. T., \& Steuber, F. A. (1965). Development Planning: Lessons of Experience. Baltimore: Johns Hopkins Press. 